\title{
Implications of Industry 4.0 to companies' performance: a comparison between Brazil and Germany ${ }^{1}$
}

\author{
Paulo Henrique Brunheroto1, Dagmar Piotr Tomanek², Fernando Deschamps ${ }^{1,3}$ \\ ${ }^{1}$ Federal University of Paraná - UFPR, Curitiba, PR, Brazil. \\ ${ }^{2}$ Technische Hochschule Ingolstadt - THI, Ingolstadt, Germany. \\ ${ }^{3}$ Pontifical Catholic University of Paraná - PUCPR, Curitiba, PR, Brazil.
}

How to cite: Brunheroto, P.H., Tomanek, D. P. and Deschamps, F. (2021), "Implications of Industry 4.0 to companies' performance: a comparison between Brazil and Germany", Brazilian Journal of Operations \& Production Management, Vol. 18, No. 3, e20211112. https://doi.org/10.14488/BJOPM.2021.009

\begin{abstract}
Goal: The present paper aims to investigate what are the main implications of Industry 4.0 technologies for production management.

Design / Methodology / Approach: The study was carried out through a survey with companies of the metal-mechanic and automotive industry of the Curitiba Metropolitan Region (Brazil) and of the Upper Bavaria Region (Germany) in order to determine the overall implementation level of technologies commonly associated with Industry 4.0 and their respective impacts to operations performance objectives.

Results: The results reveal that the overall implementation and improvement levels of the Industry 4.0 technologies is higher in Germany than in Brazil. Regarding the technologies, the Internet of Things presented one of the highest overall improvement levels for both regions, showing that the adoption of these technology could bring significant improvements for all performance objectives.

Limitations of the investigation: The results obtained with the present research refer only to the scenario of Curitiba and Metropolitan Region and the Upper Bavaria Region, more specifically from the companies of the metal-mechanic and automotive sectors and may differ from other sectors or regions.

Practical implications: From this research, companies that are willing to invest in new technologies can find a starting point to understand the benefits that they can possibly achieve based on results obtained from companies that have already adopted the technologies in Brazil and Germany.

Originality / Value: Studies that formally discuss the implications of the Industry 4.0 technologies for production management are lacking. Most studies focus excessively on the technologies without approaching their impact on management systems.
\end{abstract}

Keywords: Industry 4.0 Technologies; Production Management; Performance Objectives.

\section{INTRODUCTION}

Understanding the fourth industrial revolution, also known as "Industry 4.0", is one of the most intense and important challenges nowadays (Schwab, 2016). This new technological revolution,

\footnotetext{
${ }^{1}$ This article is from the XXVI International Conference on Industrial Engineering and Operations Management (IJCIEOM) and was invited to be published in the September/2021 Special Issue of the Brazilian Journal of Operations \& Production Management, due to its relevance and contribution to the field.
}

Financial support: BAYLAT (Bayerisches Hochschulzentrum für Lateinamerika).

Conflict of interest: The authors have no conflict of interest to declare.

Corresponding author: paulobrunheroto@hotmail.com

Received: 23 Nov 2020

Approved: 25 Nov 2020.

Editor: Francisco Gaudêncio Mendonça Freires. 
publicly named in 2011 through a German government initiative called "Industrie 4.0", was preceded by three other industrial revolutions that have driven dramatic increases in industrial productivity, being these related to the steam engine, mass production systems and automation technologies (Hermann et al., 2016; Kagemann et al., 2013; Rüßmann et al., 2015; Schwab, 2016).

Based on new and radically changed technology that aims at a fusion of the physical and the virtual world into cyber-physical systems (CPS), this topic attracted the interest of several studies, many related to the technologies being used, such as the Internet of Things (IoT) and computational techniques associated with artificial intelligence and the processing of large volumes of data (Big Data Analytics) (Bechtold et al., 2014; Dujin et al., 2014; Liao et al., 2017). However, studies that formally discuss the implications of these technologies for production management are lacking, focusing excessively on the technologies without approaching their impact on management systems.

Based on this context, the present research aims to support the understanding of how these technologies are impacting production management. For this, a survey was made with companies of the metal-mechanic and automotive industry of the Curitiba Metropolitan Region (Brazil) and of the Upper Bavaria Region (Germany), aiming to determine the overall implementation level of these technologies and their respective impacts to operations performance objectives.

Therefore, the present paper is organized in four sections. In the next section, some concepts are presented in relation to the information used for the development of the questionnaire. After that, the research methodology used for the questionnaire construction and data processing is shown. Then, results and discussions regarding the survey are presented. Finally, in the last section, conclusions obtained with the present research are drawn.

\section{THEORETICAL BACKGROUND}

\section{Industry 4.0 technologies}

For the assessment of technologies associated with Industry 4.0, the 27 technologies organized by Brunheroto et al. (2018) were taken as basis. Then, based on the number of uses of each technology on Brunheroto et al.'s (2018) research and the number of appearances of them on consulting reports, technologies were filtered as shown in Figure 1, resulting in 6 technologies to be used for the present analysis (Bechtold et al., 2014; Brunheroto et al., 2018; Dujin et al., 2014; Reinhard et al., 2016; Rüßmann et al., 2015; Wee et al., 2015).

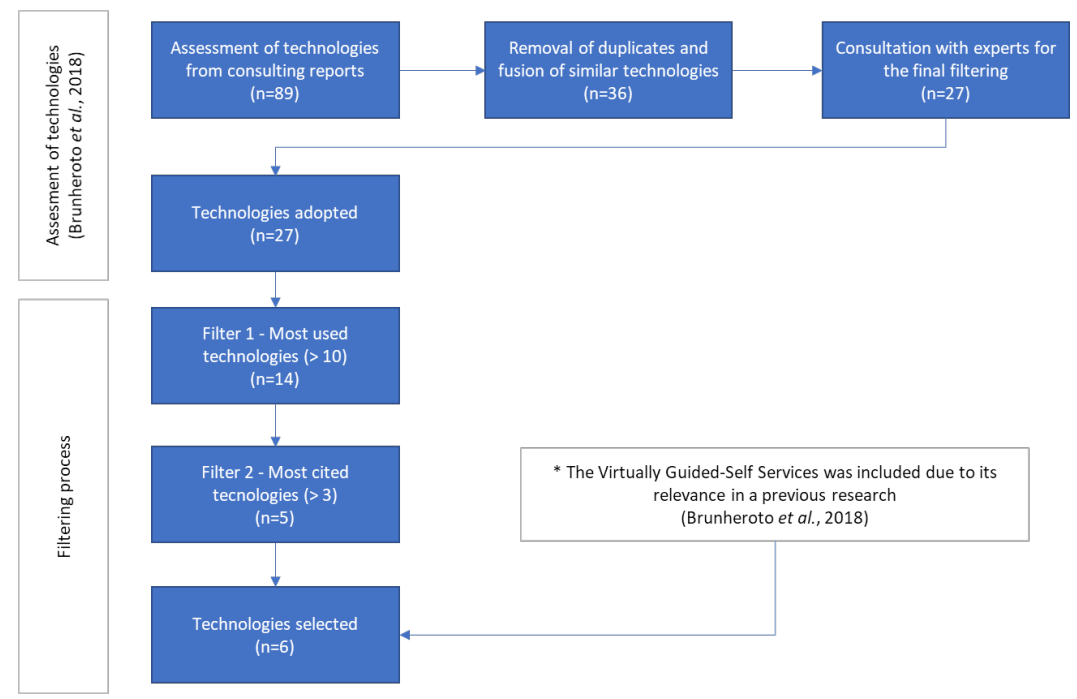

Figure 1. Filtering process (Overview). Source: The authors themselves

As seen in Figure 1, the six technologies were chosen based on their number of uses $(>10)$ and the number of appearances $(>3)$ on the five consulting reports used to assess the 
27 previous technologies organized by Brunheroto et al.'s (2018) research. However, due to the relevance of the Virtually Guided Self-Services to this research, it was also included on the final set, even not being cited as many times by the consulting reports.

Therefore, six technologies were selected to be used in the analysis of the implications of their adoption to operations performance objectives: "Internet of Things", "Cloud", "Cybersecurity”, “Big Data Analytics", "Virtually Guided Self-Services” and "3D Printing".

\section{Performance Objectives}

Performance objectives describes what the manufacturing function should achieve in order to satisfy market requirements (Andersson and Bellgran, 2015; Kim and Arnold, 1996; Slack and Lewis, 2015). About the definition of this set, many authors on operations strategy have their own set of performance objectives (Slack and Lewis, 2015). Therefore, for the present research the model proposed by Slack and Lewis (2015) and Corrêa and Corrêa (2012) was chosen, where five performance objectives are considered: "Dependability", "Cost", "Flexibility", "Quality" and "Speed". The definitions for each one of this objectives can be seen in Table 1.

Table 1. Performance objectives

\begin{tabular}{ll}
\hline \multicolumn{1}{c}{ Objective } & \multicolumn{1}{c}{ Definition } \\
\hline Dependability & $\begin{array}{l}\text { Carrying out the work in a timely manner, abiding by the delivery commitments } \\
\text { promised to the customers. }\end{array}$ \\
\hline Cost & $\begin{array}{l}\text { Carrying out the work in an inexpensive manner. } \\
\text { Flexibility }\end{array}$ \\
\hline Quality & $\begin{array}{l}\text { The ability to change or match the activities of operations to overcome unexpected } \\
\text { circumstances or introducing new products or services. }\end{array}$ \\
\hline Speed & $\begin{array}{l}\text { Performing tasks properly, producing and procuring goods and services without } \\
\text { error and in accordance with the previously determined goals. }\end{array}$ \\
\hline
\end{tabular}

Source: Designed from Kaviani and Abbasi (2014)

\section{METHOD}

\section{Universe definition}

For the universe definition of the metal-mechanic and automotive companies of the Curitiba Metropolitan Region (Brazil) and the Upper Bavaria Region (Germany), databases, made available by FIEP (Federação das Indústrias do Estado do Paraná) and Bayern International, were used (Bayern International, 2019; Federação das Indústrias do Estado do Paraná, 2019). In these databases, filters were made, and 762 companies were found for the Curitiba Metropolitan Region and 690 for Upper Bavaria as the universe of companies for the present research. Regarding the regions, 29 cities were considered as being part of the Curitiba Metropolitan Region and 23 cities for Upper Bavaria (Bezirk Oberbayern, 2019; Coordenação da Região Metropolitana de Curitiba, 2017).

\section{Questionnaire construction}

Once the universe of companies was defined, the next step was constructing the questionnaire. For this, a questionnaire, hosted on Online Pesquisa, was developed based on the information gathered in the theoretical background. Regarding the structure of the questionnaire, it was divided in a presentation section, four main sections and a last section for participant's feedback. In the first section, information about the questionnaire was presented, such as research objective, estimated response time, confidentiality of 
information, contact information, among others. After this presentation, the questionnaire was further divided into four main sections, which are described next.

The first two main sections consist of respondent information and information about the implementation level by the respondent's company of the six technologies previously described described. The respondent was asked to inform, in a level from 1 (we don't have) to 5 (we have advanced implementation) the implementation level of each technology, similar to the model proposed by Frank et al. (2019).

Based on that information, in the last two main sections, concepts regarding operations performance objectives were presented and the respondent was asked to inform, in a level from 1 (none) to 5 (excellent), the improvement level in each one of the performance objectives due to the implementation of the technologies selected in the previous sections. Finally, the last section consisted in a feedback section, in which the respondent could provide feedback regarding the questionnaire.

\section{Collection of responses}

Questionnaires were sent by e-mail to the whole universe mentioned previously, with some other relevant information. After the first round of e-mails, adjustments were made to the e-mail list, since some of the companies had closed or had the wrong contact information, being later sent to the correct contacts.

After the questionnaire was sent to the entire universe, further actions were still necessary to collect responses, which are briefly described next. The first one was the preparation of a questionnaire in a document format, due to some possible problems with access to the link from companies that have restrictions on Internet access. For this, the questionnaire was rewritten and resent in Microsoft Word (DOC and DOCX) and Portable Document Format (PDF) formats, aiming to solve this problem.

The second measure carried out was in relation to the risk of the e-mail sent having been redirected to the potential respondent's spam box or the recycle bin. For this, after the preliminary submissions (link and attached document), a warning was sent to the whole universe, without any link or attachment, regarding the last e-mails and informing the deadline for the responses, asking to request the resending of the e-mails in case of non-receipt.

After these two actions related to questionnaire access, a last round of e-mails, with the link and the attachments, were sent on the last week of the collection period, aiming to remind the companies of the deadline.

\section{Data processing}

Responses were exported from the survey platform, briefly organized in Microsoft Excel and then sent to the Microsoft Power BI platform for final organization and reports generation for each country. Regarding these reports, they are divided in 4 main sections:

- Sample Data: For the sample data section, pie charts regarding the companies' size and sector were constructed, as well as a map indicating the cities of the participant companies and graphs presenting the participation status, including the incomplete and complete responses, number of respondents and number of respondent companies.

- Comparative: On the second section, a comparison between the Brazilian and German scenarios is done regarding the improvement level and the adoption percentage of each technology. For the improvement comparison, spider graphs, similar to the explained above, and columns graphs were created, aiming to identify the differences on the average improvement level for each technology. Besides that, a table was also constructed aiming to identify the number of technologies being adopted for each country and their respective implementation levels.

- Implementation: The implementation section aims to analyze the implementation level of each technology. For this, pie and bar charts were respectively created to present the implementation level responses and the number of uses of each 
technology. Besides that, a table and a dispersion graph were also generated, aiming to analyze the average implementation level and standard deviation for each technology through different sizes of companies.

- Improvement: For the improvement section, spider and boxplot graphs were constructed, as well as a table with the average improvement level and the standard deviation for each technology in each performance objective. In relation to the spider graph, it was created aiming to facilitate the visualization of which performance objective was more impacted by the adoption of each technology. Finally, regarding the boxplots and the table, they were generated to analyze the responses distribution and identify if the improvements are generally the same or if they have discrepancies according to different contexts of applications (companies' size, sector, etc.).

\section{RESULTS AND DISCUSSION}

For a better understanding of the present research, results are divided according to the questionnaire sequence, being presented first the sample data, followed by the implementation level and the improvement level results. Regarding the results of the comparative section, they are included in the implementation and improvement sections and, therefore, will not be presented separately.

\section{Sample data}

Using the method described previously, 76 responses from 63 companies were obtained for the Curitiba Metropolitan Region and 26 responses from 24 companies for Upper Bavaria, including some incomplete responses that could be used for the analysis ( 7 for each country). The size of the respondent companies according to SEBRAE criteria (Serviço Brasileiro de Apoio às Micro e Pequenas Empresas, 2015), can be seen, respectively, on Figure 2 and Figure 3.

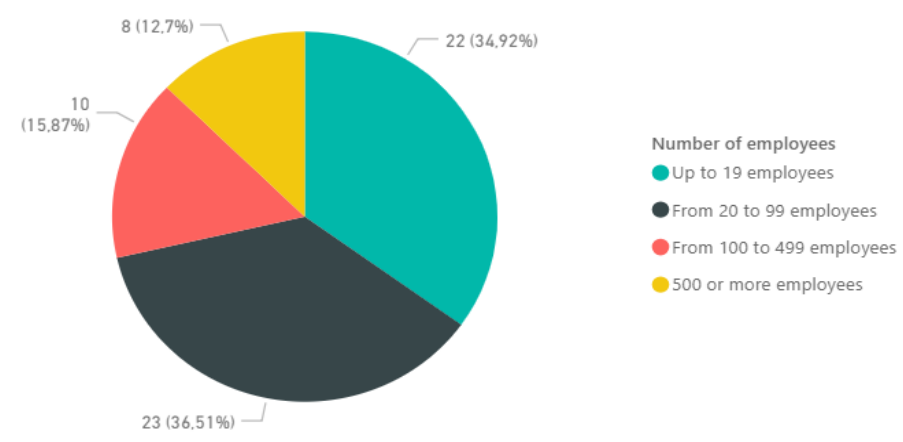

Figure 2. Companies size (Brazil). Source: The authors themselves

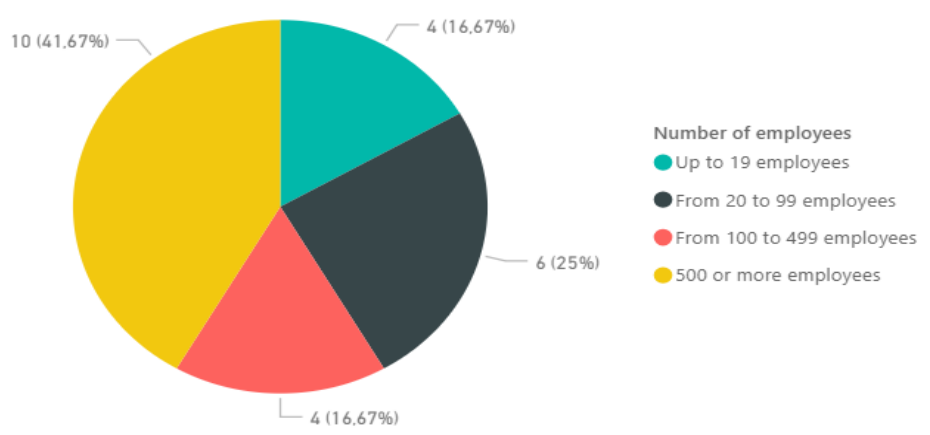

Figure 3. Companies size (Germany). Source: The authors themselves

As seen in Figure 2, great part of the responses were from micro and small companies, which represent more than $80 \%$ of the universe of companies in the Curitiba Metropolitan 
Region. However, it should also be noted that the number of responses from large companies, which represent less than $5 \%$ of the universe, had a considerable response rate on this study. Regarding the reasons for this great diversity of sizes, it can be related to the interest regarding the subject (Industry 4.0), that attracts more interest from companies that are trying implementing those technologies, which are usually the larger companies, and the easier access to larger companies throughout internal contacts and by the number of employees itself, since it has more possibilities of contacts inside the company.

In relation to the responses of the Upper Bavaria (Figure 3), it can be seen that, differently from the Brazilian responses, great part of the participants were from large companies, even being harder to approach due to the lack of internal contacts. Regarding the reason for these considerable number of large companies participating on the study, it can also be related to the interest regarding the theme (Industry 4.0), but mainly due to the amount of large companies existent in the Upper Bavaria, since the headquarters of several automotive companies are located in this region.

\section{Implementation levels}

Regarding the average implementation levels obtained for both regions, they can be observed in Table 2. Besides that, the results for Brazil and Germany regarding the average implementation level of each technology by the companies' size can be seen, respectively, in Figure 4 and Figure 5.

Table 2. Average implementation levels

\begin{tabular}{lcc}
\hline \multicolumn{1}{c}{ Technology } & Brazil & Germany \\
Internet of Things & 1,96 & 3,19 \\
\hline Cloud & 2,41 & 3,15 \\
\hline Cybersecurity & 3,04 & 3,62 \\
\hline Big Data Analytics & 2,06 & 3,30 \\
\hline Virtually Guided Self-Services & 2,44 & 3,15 \\
3D Printing & 2,14 & 2,90 \\
\hline
\end{tabular}

Source: The authors themselves

As shown in Table 2, the overall implementation level of the German companies is higher than the Brazilian companies, being this even more considerable for some technologies such as Internet of Things, which has an average implementation level of 1,96 for Brazilian companies against 3,19 for German companies. Regarding these differences, it can be explained by two main reasons. The first one is related to the regions itself, since the concept of Industry 4.0 started in Germany and it has more consolidated culture of adopting technologies and, as stated early, great part of the headquarters are located in this region, in which usually these technologies are developed before spreading to other sides around the world. Regarding the second reason, it can be related to the sample, since for the German sample $41,67 \%$ were large companies (Figure 3), against $12,7 \%$ of the Brazilian companies (Figure 2), which can reflect directly on these average results, since the higher adoption levels are usually associated with the larger companies.

Therefore, for this reason, the results were split by the companies' size, resulting the graphs shown in Figure 4 and Figure 5. Regarding these graphs, the center of the circles represents the average implementation levels and the circles radius their respective standard deviation, being the larger circles radius associated with greater standard deviations and viceversa. 


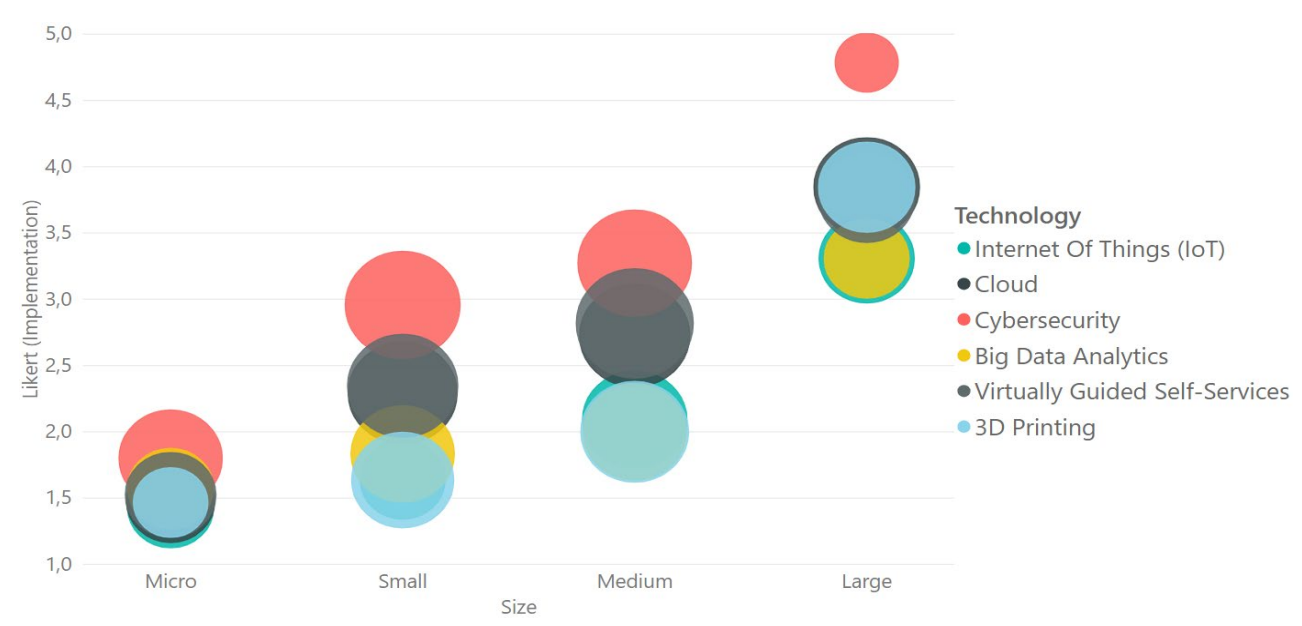

Figure 4. Average implementation levels per size (Brazil). Source: The authors themselves

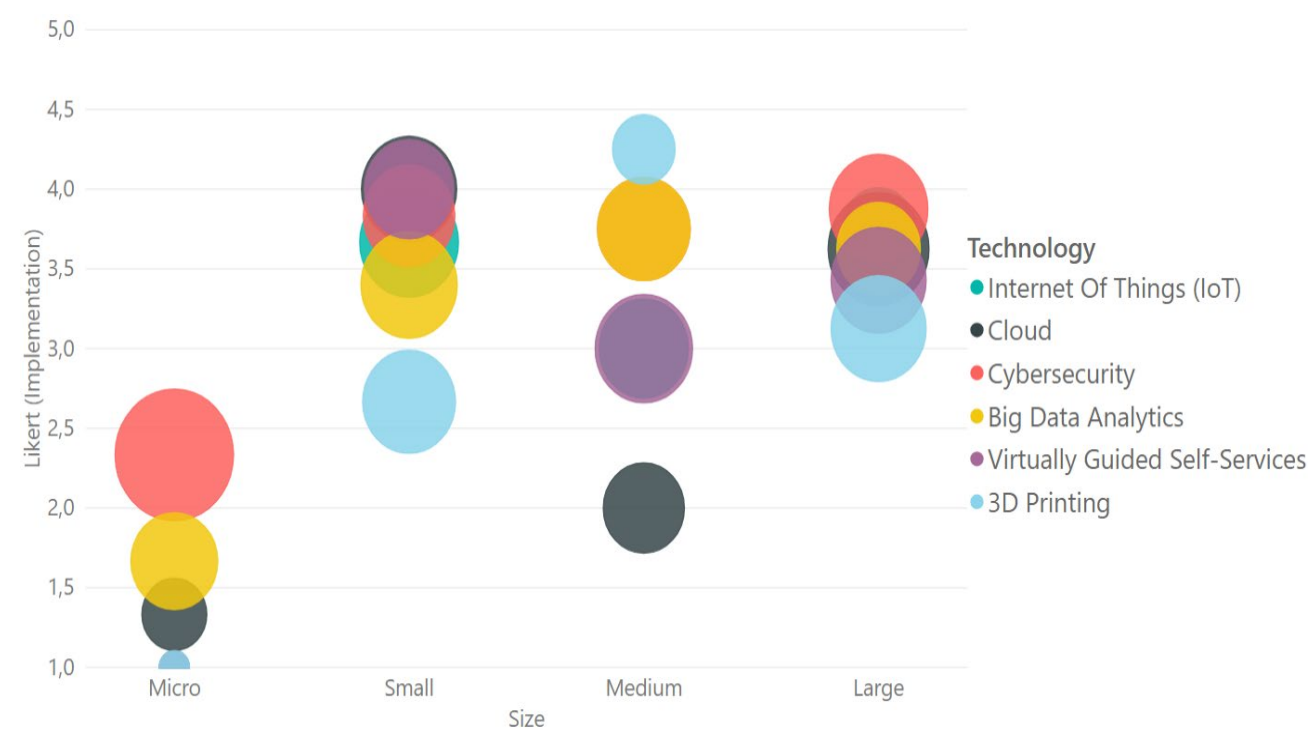

Figure 5. Average implementation levels per size (Germany). Source: The authors themselves

As seen in Figure 4, the average adoption level of the technologies increases according to the companies' size, being the results for the large companies significantly higher comparing to the other companies, showing that the low average implementation levels of the Table 2 is not a reality for all size of companies.

However, for the German results (Figure 5), these adoption level increase according to the companies' size is not observed, being the small companies with the higher average implementation levels of "Cloud" and "Virtually Guided Self-Services", the medium with the "3D Printing" and "Big Data Analytics" and the large with "Cybersecurity" and "Internet of Things", showing that the higher implementation levels seen in Table 2 are not exclusive for some size of company, as observed in the Brazilian results.

Therefore, the association between company size and implementation level is not a completely true for both sides, being the technologies of the German companies more well distributed and with a higher overall implementation level, showing that the technologies are accessible for all size of companies.

\section{Improvement levels}

Regarding the average improvement levels obtained for Brazil and Germany, they can be observed, respectively, in Tables 3 and 4. 
Table 3. Average improvement levels (Brazil)

\begin{tabular}{lccccc}
\hline \multicolumn{1}{c}{ Technology } & Depend. & Cost & Flexibility & Quality & Speed \\
Internet of Things & 3,64 & 3,18 & 3,09 & 3,55 & 3,27 \\
\hline Cloud & 3,38 & 2,83 & 3,29 & 3,29 & 3,08 \\
\hline Cybersecurity & 3,81 & 2,95 & 2,97 & 3,62 & 3,32 \\
\hline Big Data Analytics & 3,07 & 3,07 & 2,86 & 3,14 & 3,14 \\
\hline Virtually Guided & 3,39 & 3,00 & 3,09 & 3,26 & 3,13 \\
\hline Self-Services & 3,50 & 3,29 & 3,86 & 3,36 & 3,50 \\
\hline 3D Printing & & & & & \\
\hline
\end{tabular}

Source: The authors themselves

Table 4. Average improvement levels (Germany)

\begin{tabular}{lccccc}
\hline \multicolumn{1}{c}{ Technology } & Depend. & Cost & Flexibility & Quality & Speed \\
\hline Internet of Things & 3,89 & 3,44 & 3,78 & 3,89 & 4,33 \\
Cloud & 3,56 & 3,56 & 3,67 & 3,44 & 3,44 \\
\hline Cybersecurity & 4,11 & 2,30 & 2,60 & 3,10 & 2,70 \\
\hline Big Data Analytics & 3,56 & 3,25 & 3,44 & 3,78 & 3,67 \\
\hline Virtually Guided & 3,89 & 3,00 & 3,00 & 3,56 & 2,89 \\
\hline Self-Services & 2,43 & 3,14 & 4,14 & 2,57 & 4,00 \\
3D Printing & & & & & \\
\hline
\end{tabular}

Source: The authors themselves

As observed in Table 3 and Table 4, the overall improvement levels of the German companies were slightly higher than the Brazilian companies. However, comparing the results individually for each technology, it can be observed that not all technologies of the German companies had higher average improvement levels in all performance objectives, and they do not necessarily follow the same pattern of the most improved objectives.

Taking the "Internet of Things" and "3D Printing" as example, for the Brazilian companies (Table 3), the most improved aspect by adopting loT was "Dependability", while for the German companies (Table 4) was "Speed". Regarding these differences, it can be related to the way that this technology is being used by the companies, since, as observed in Figure 5, the Internet of Things has a high implementation level in other sizes of companies than the large ones, as observed in Brazil (Figure 4). Therefore, as in Brazil usually the loT is usually used by the large companies for data collection to increase the dependability and quality of their processes, in Germany it has a wider range of companies using it, being the flexibility and speed one of the main goals of the small and medium companies.

As for the "3D Printing", the results of both scenarios are quite different, being the "Dependability", which was one of the main improved objectives for the Brazilian scenario, the less improved aspect for the German scenario. Regarding this difference, it can be explained to two main reasons. The first one is related to the companies that are adopting it, since, as stated early, the "3D Printing" has the higher implementation level in medium companies in Germany (Figure 5) and in large companies in Brazil (Figure 4), which can have different goals for the adoption, as exemplified early with the IoT. However, the second reason could be related to the precision needed for both scenarios, since the medium companies (German scenario) are usually suppliers and probably uses the 3D Printing for manufacture their products and, due the strictness imposed by their clients, which includes headquarters of large automotive and defense companies, the improvements could not be enough in terms of dependability and quality, while the large companies (Brazilian scenario), besides the manufacture of parts, also can use the technology for prototyping and development of new products and, therefore, the adoption in terms dependability and quality show as a good solution for this application. 


\section{CONCLUSION}

Through the presented method, it can be said that the objective of identify the main implications of the Industry 4.0 technologies for the production management was achieved, since a survey of two different regions regarding the overall implementation level and their implication to the performance objectives could be performed. However, it should be noted that the results presented refer only to the scenario of Curitiba and Metropolitan Region and the Upper Bavaria, more specifically of the companies of the metal-mechanic and automotive sector and may differ from other sectors or regions studied.

As presented in the topic of results and discussion, the overall implementation level of the Industry 4.0 technologies of the German companies is higher than the Brazilian companies, being this difference even more considerable for some technologies such as the Internet of Things. However, it should be noted that great part of the adoptions in Brazil is concentrated in the large companies, being the overall implementation level of the small and medium companies much lower when compared to the large companies. In Germany, however, the adoptions are more well distributed, being the small companies with the highest average implementation level of "Cloud" for example, showing that the technologies are more accessible for different sizes of companies.

In relation to the improvement levels, the results for the German companies were slightly higher than the Brazilian companies. However, comparing the results individually, is possible to identify that not all technologies have the same pattern of improvement for both regions, which, as stated early, could be related to the size of the companies, since companies of different sizes and regions can have different goals and, therefore, different ways for adopting the same technology.

Therefore, it can be concluded that even with the constant adoption of Industry 4.0 technologies, not all technologies seem to be accessible in Brazil as in Germany, being the adoptions usually restricted for the larger companies. Regarding the improvement levels, the Internet of Things presented one of the highest overall improvement levels for both regions comparing to the other technologies, showing that the adoption of these technology could bring significant improvements for all performance objectives, being the higher improvements related to "Speed" in the German scenario and "Dependability" in the Brazilian scenario.

Finally, for future works, it is suggested to apply the proposed methodology to other regions and sectors to analyze the differences between the applications in different scenarios. In addition, case studies are also suggested related to these adoptions, aiming to understand how that adoptions occurred and the reasons for these differences between regions.

\section{REFERENCES}

Andersson, C. and Bellgran, M. (2015), "On the complexity of using performance measures: enhancing sustained production improvement capability by combining OEE and productivity", Journal of Manufacturing Systems, Vol. 35, pp. 144-54.

Bayern International (2019), "Key to Bavaria: the Foreign Trade Database", Bavarian Bureau for International Business Relations, available at: https://www.bayern-international.de/en/companydatabase/ (accessed 25 July 2019).

Bechtold, J., Kern, A., Lauenstein, C. et al. (2014), Industry 4.0: the Capgemini Consulting View, Capgemini Consulting, Paris, pp. 1-31.

Bezirk Oberbayern (2019), Bezirk Oberbayern 2019: Zahlen Und Daten, Bezirk Oberbayern, München.

Brunheroto, P.H., Ling, B.P., Deschamps, F. et al. (2018), “Como as Tecnologias da Indústria 4.0 Estão Sendo Aplicadas? Um Survey das Indústrias do Setor Metal-Mecânico e Automobilístico de Curitiba e Região Metropolitana", in XXXVIII Encontro Nacional de Engenharia de Produção, ABEPRO, Rio de Janeiro, pp. 1-13. http://dx.doi.org/10.14488/ENEGEP2018_TN_STO_264_515_36525.

Coordenação da Região Metropolitana de Curitiba - COMEC (2017), Revista da Região Metropolitana de Curitiba, COMEC, Curitiba.

Corrêa, H.L. and Corrêa, C.A. (2012), Administração de Produção e Operações: Manufatura e Serviços: uma Abordagem Estratégica, 3rd ed., Editora Atlas SA., São Paulo. 
Dujin, A., Geissler, C. and Horstkötter, D. (2014), Industry 4.0: the New Industrial Revolution How Europe Will Succeed, Roland Berger Strategy Consultants, Munich.

Federação das Indústrias do Estado do Paraná - FIEP (2019), Cadastro das Indústrias do Paraná: 2019, Sistema FIEP, Curitiba.

Frank, A.G., Dalenogare, L.S. and Ayala, N.F. (2019), "Industry 4.0 technologies: Implementation patterns in manufacturing companies", International Journal of Production Economics, Vol. 210, pp. 15-26. http://dx.doi.org/10.1016/j.ijpe.2019.01.004.

Hermann, M., Pentek, T. and Otto, B. (2016), "Design principles for industrie 4.0 scenarios”, Proceedings of the Annual Hawaii International Conference on System Sciences, Vol. 2016, pp. 3928-3937. http://dx.doi.org/10.1109/HICSS.2016.488.

Kagemann, H., Wahlster, W. and Helbig, J. (2013), Recommendations for Implementing the STRATEGIC INITIATIVE Industrie 4.0, Acatech, Frankfurt, pp. 1-80.

Kaviani, M.A. and Abbasi, M. (2014), "Analysing the operations strategies of manufacturing firms using a hybrid Grey DEA approach: a case of Fars Cement Companies in Iran", International Journal of Supply and Operations Management, Vol. 1, No. 3, pp. 371-91.

Kim, J.S. and Arnold, P. (1996), "Operationalizing manufacturing strategy", International Journal of Operations \& Production Management, Vol. 16, No. 12, pp. 45-73. http://dx.doi.org/10.1108/01443579610151751.

Liao, Y., Deschamps, F., Loures, E.F.R. et al. (2017), "Past, present and future of Industry 4.0 - a systematic literature review and research agenda proposal", International Journal of Production Research, Vol. 55, No. 12, pp. 3609-29. http://dx.doi.org/10.1080/00207543.2017.1308576.

Reinhard, G., Jesper, V. and Stefan, S. (2016), Industry 4.0: Building the Digital Enterprise, Price Waterhouse Coopers, United Kingdom, pp. 1-39.

Rüßmann, M., Lorenz, M., Gerbert, P. et al. (2015), Industry 4.0: the Future of Productivity and Growth in Manufacturing Industries, The Boston Consulting Group, Boston, pp. 1-20.

Schwab, K. (2016), The Fourth Industrial Revolution, VINT Research Report, World Economic Forum, Geneva. https://doi.org/10.1017/CBO9781107415324.004.

Serviço Brasileiro de Apoio às Micro e Pequenas Empresas - SEBRAE. (2015), Anuário do Trabalho na Micro e Pequena Empresa: 2014, SEBRAE, Departamento Intersindical de Estatística e Estudos Socioeconômicos, Brasília.

Slack, N. and Lewis, M. (2015), Operations Strategy, Wiley Encyclopedia of Management, 3rd ed., Pearson, Harlow. https://doi.org/10.1002/9781118785317.weom100160.

Wee, D., Kelly, R., Cattel, J. et al. (2015), Industry 4.0: How to Navigate Digitization of the Manufacturing Sector, McKinsey \& Company, pp. 1-62.

Author contributions: Paulo Henrique Brunheroto: All processes - questionnaire construction, data collection, analysis, management and writing. Dagmar Piotr Tomanek: German advisor - questionnaire translation, data collection, management and additional supports. Fernando Deschamps: Main advisor - questionnaire construction, data collection, management and additional supports 